Www.jmscr.igmpublication.org

Index Copernicus Value: 79.54

ISSN (e)-2347-176x ISSN (p) 2455-0450

crossrefDOI: https://dx.doi.org/10.18535/jmscr/v7i3.159

\title{
Prevalence of Glaucoma in stress conditions
}

\section{Dr Neeta Bajaj Gawhale*, Dr Manjiri Sankpal, Dr Nikita Harwani, Dr Sumedha Vikram}

G.T Hospital under GGMC\& J.J Group of hospitals

*Corresponding Author

Dr Neeta Bajaj Gawhale

Asso. Prof and HOU, Dept. of Ophthal, G.T Hospital under GGMC \& J.J Group of Hospitals

\begin{abstract}
600 people screened for glaucoma. Divided in 2 groups. First with strenuous work of 12-14hrs / day 2nd grp with sedentary won for 7-8hrs /day. Parameters used were IOT, gonioscopy, perimeter, oct where ever required

Result: Out of the 300 people with strenuous working group 13 people were positive for glaucoma as compared to non strenous group which showed only 6 people had glaucoma.
\end{abstract}

\section{Introduction}

Glaucoma is a condition which is a preventable cause of blindness. It is a progressive optic neuropathy with characteristic optic nerve head changes which may be associated with raised intraocular pressure and visual field defects. In our study 600 patients were screened for glaucoma. The parameters used to test glaucoma were intraocular pressure, perimetry, gonioscopy and ocular computed tomography whenever required.

\section{Method}

600 patients were divided into 2 groups of 300 patients each. In one group all patients had strenuous $^{(1)}$ working hours of 12-14 hrs per day, while the other group had working hours of 4-6 hrs per day. All the patients were screened for glaucoma by recording best corrected visual acuity, intraocular pressure and perimetry.
Gonioscopy and OCT were done to confirm the diagnosis.

\section{Observation}

The two groups showed the following observations.

In the first group that had patients with longer working hours of $12-14 \mathrm{hrs}$, findings were as follows-

Out of the 300 patients

- 25 had optic disc changes suggestive of glaucoma

- 14 had raised intraocular tension

- 20 had changes on perimetry

- 10 showed thinning of nerve fibre layer in optic disc

- All 25 patients with optic disc changes had reduced visual acuity ranging from $6 / 24$ to $6 / 9$ 
In the second group that had patients with shorter working hours of 4-6hrs, findings were as follows-

Out of the 300 patients

- 12 had optic disc changes

- 8 had high intraocular tension

- 6 had visual field restriction defects on perimetry

- 4 had changes in OCT

\section{Result}

$10-12 \%$ people exposed to stress in the form of longer working hours had glaucoma while only 6$7 \%$ of people exposed to shorter working hours had glaucoma.

\section{Conclusion}

It was concluded that stress was a definitive risk factor $^{(2)}$ for development of glaucoma

\section{References}

1. Kaluza G, Maurer H. Stress and intraocular pressure in open angle glaucoma. PsycholHealth . 2007 Dec 19 [cited 2019 Mar 11];

2. Shily BG. Psychophysiological stress, elevated intraocular pressure, and acute closed-angle glaucoma. Am J Optom Physiol Opt. 1987 Nov;64(11):866-70. 